Kansas State University Libraries

New Prairie Press

\title{
ESTIMATION OF CARDINAL TEMPERATURES IN GERMINATION DATA ANALYSIS
}

Cindy Roche

Bahman Shafii

Donald C. Thill

William J. Price

See next page for additional authors

Follow this and additional works at: https://newprairiepress.org/agstatconference

Part of the Agriculture Commons, and the Applied Statistics Commons

\section{(c) (i) $(9)$}

This work is licensed under a Creative Commons Attribution-Noncommercial-No Derivative Works 4.0 License.

\section{Recommended Citation}

Roche, Cindy; Shafii, Bahman; Thill, Donald C.; and Price, William J. (1996). "ESTIMATION OF CARDINAL TEMPERATURES IN GERMINATION DATA ANALYSIS," Conference on Applied Statistics in Agriculture. https://doi.org/10.4148/2475-7772.1316

This is brought to you for free and open access by the Conferences at New Prairie Press. It has been accepted for inclusion in Conference on Applied Statistics in Agriculture by an authorized administrator of New Prairie Press. For more information, please contact cads@k-state.edu. 
Author Information

Cindy Roche, Bahman Shafii, Donald C. Thill, and William J. Price 


\title{
ESTIMATION OF CARDINAL TEMPERATURES IN GERMINATION DATA ANALYSIS
}

\author{
Cindy Roché ${ }^{1}$, Bahman Shafii ${ }^{2}$, \\ Donald C. Thill ${ }^{1}$, and William J. Price ${ }^{2}$ \\ ${ }^{1}$ Division of Plant Sciences \\ ${ }^{2}$ Statistical Programs \\ College of Agriculture \\ University of Idaho \\ Moscow, Idaho 83844
}

\begin{abstract}
Seed germination is a complex biological process which is influenced by various environmental and genetic factors. The effects of temperature on plant development are the basis for models used to predict the timing of germination. Estimation of the cardinal temperatures, including base, optimum, and maximum, is essential because rate of development increases between base and optimum, decreases between optimum and maximum, and ceases above the maximum and below the base temperature. Nonlinear growth curves can be specified to model the time course of germination at various temperatures. Quantiles of such models are regressed on temperature to estimate cardinal quantities. Bootstrap simulation techniques may then be employed to assure the statistical accuracy of these estimates and to provide approximate nonparametric confidence intervals. A statistical approach to modelling germination is presented and application is demonstrated with reference to replicated experiments designed to determine the effect of temperature gradient on germination of three populations of an introduced weed species common crupina (Crupina vulgaris Pers.).
\end{abstract}

\section{INTRODUCTION}

The process of seed germination begins as the seed coat imbibes water, progresses through physiological growth and development of the embryo accessing stored reserves, and culminates in emergence of the radical or hypocotyl. Typically, cumulative germination of a population of seeds over time appears as an S-shaped curve, in which a lag phase representing delay in onset during initial water uptake is followed by an increasing, approximately linear phase representing the rate of physiological activity leading to radical emergence, and ends with an upper asymptote at the maximum germination percentage. The ideal description of germination should be complete, concise, unambiguous, and amendable to statistical analysis (Brown and Mayer 1988), and should provide information on all three phases of the curve: lag, rate, and extent of germination.

Traditional methods of germination data analysis include single-value indices and the method of moments. Indices have been used to emphasize independent aspects of germination or to distinguish superior from inferior germination (Kotowski 1926, Maguire 1962, Timson 
1965). In the method of moments, statistics such as total, mean, variance of time to germination, quartiles, and percentiles are used to represent the process and assimilate final germination (Tucker and Wright 1965, Nicholls and Heydecker 1968, Orchard 1977). Indices and moments have several limitations, including (1) failure to supply essential information about onset, rate of dispersion in time and extent of germination, (2) ambiguity and incompleteness, (3) restrictive distributional assumptions, and (4) failure to describe, rather than simply represent, the germination process.

Thus, growth models have become a preferred method of defining the germination process (Janssen 1973, Tipton 1984, Brown and Mayer 1988, Torres and Frutes 1990, Shafii et al. 1991). Given the correct mathematical specification along with the appropriate statistical estimation procedure, this approach provides functional information resulting in parameter estimates with relevant biological interpretations.

Germination is affected by many factors, both genetic and environmental, including the environment of the plant during seed maturation. Water potential, temperature, light quality and quantity, aeration, and other factors related to seed age and dormancy influence the germination process. For nondormant seeds with adequate moisture, temperature is often the main environmental factor governing germination.

The effect of temperature on plant development is the basis for models used to predict timing of germination of seeds in moist soil. Because the characteristics of cumulative germination vary by temperature, an alternative to comparing germination curves from different temperature regimes is to define the cardinal temperatures (Garcia-Huidobro et al. 1982), and then to estimate the thermal time requirement for germination with data from all temperatures on a single curve. Cardinal temperatures of base $\left(T_{b}\right)$ and maximum $\left(T_{m}\right)$ delimit the range for potential germination. Conventionally, germination rate $\left(1 / t_{50}\right)$, the inverse of time to $50 \%$ germination, is plotted against the temperature gradient (Figure 1). Germination rate increases above $T_{b}$ towards an optimum temperature $\left(T_{0}\right)$ then declines as temperature increases toward $\mathrm{T}_{\mathrm{m}}$. Because germination becomes very slow and seed mortality is very high near the lower and upper temperature limits, $\mathrm{T}_{\mathrm{b}}$ and $\mathrm{T}_{\mathrm{m}}$ are estimated via extrapolation.

The objective of this paper is to present a statistical approach to modelling germination and estimation of cardinal temperatures in three populations of common crupina naturalized in the Pacific Northwest.

\section{METHODS}

Many mathematical models have been proposed to describe the time course of germination (Brown and Mayer 1988; Shafii et al. 1991). A majority of these nonlinear asymptotic growth models can provide parameter estimates with relevant biological interpretations. For this study, an excellent fit was obtained using the logistic function of the form:

$$
\mathrm{y}=\mathrm{M}\left[1+\exp \left(-\mathrm{K}^{*}(\mathrm{t}-\mathrm{L})\right)\right]^{-1}
$$

where

$\mathrm{y}=$ cumulative percentage germination at time $\mathrm{t}$, $\mathrm{M}=$ asymptote (theoretical maximum for $\mathrm{y}$ ), 


$$
\begin{aligned}
& \mathrm{K}=\text { rate of increase, and } \\
& \mathrm{L}=\text { time scale (lag related) constant. }
\end{aligned}
$$

This function has been widely used in modelling germination data (Dumur et al. 1990; Shafii et al. 1991; Thompson et al. 1994), is sigmoidal and symmetrical, and similar to the cumulative normal distribution. Parameter estimation is accomplished using a nonlinear least squares technique, e.g. the Gauss-Newton algorithm.

Parameter $L$ in equation (1) measures the time required to reach $50 \%\left(t_{50}\right)$ of maximum potential germination (M). Alternatively, the function may be modified (scaled) to estimate time to different germination percentiles. Estimated values of $\mathrm{L}$ obtained from a series of experiments over a range of constant temperatures may be used to define the onset and spread of germination.

Estimates of cardinal temperatures were obtained by regression of $1 / L\left(L=t_{50}\right)$ against the temperature gradient. This was best modelled using a parabolic regression equation of the form:

$$
1 / \mathrm{L}=\beta_{0}+\beta_{1} \text { temp }+\beta_{2} \text { temp }^{2}+\epsilon
$$

where $\beta_{0}, \beta_{1}$ and $\beta_{2}$ are the intercept and first and second order coefficients, and $\epsilon$ is the error term. While the estimated value for $T_{o}$ was calculated by differentiation, those for $T_{b}$ and $T_{m}$ were obtained by extrapolation to the intercept with the abscissa.

Values for cardinal temperatures are often reported without any measures of statistical accuracy. Statistical confidence intervals for the base, maximum, and optimum temperatures can be developed using simulation methods, such as the bootstrap. In the bootstrap technique several samples are taken from the data with replacement. The estimation procedure is applied to each sample, thereby generating a large set of parameter estimates with their corresponding frequency distributions. Percentile intervals (Efron and Tibshirani 1993) may then be constructed based on the percentiles of the bootstrap distribution.

Let $\hat{G}$ be the cumulative distribution function of the estimator $\hat{\theta}$. Then, the $1-2 \alpha$ percentile interval is given by

$$
\left[\hat{\theta}_{\% \mathrm{~L}}, \hat{\theta}_{\% \mathrm{U}}\right] \approx\left[\hat{\mathrm{G}}^{-1}(\alpha), \hat{\mathrm{G}}^{-1}(1-\alpha)\right]
$$

For a finite number (B) of bootstrap replications, and given $\hat{G}^{-1}(\alpha)=\hat{\theta}(\alpha)$ for the bootstrap distribution, the approximate $1-2 \alpha$ percentile interval is

$$
\left[\hat{\theta}_{\% \mathrm{~L}}, \hat{\theta}_{\% \mathrm{U}}\right] \approx\left[\hat{\theta}_{\mathrm{B}}(\alpha), \hat{\theta}_{\mathrm{B}}(1-\alpha)\right]
$$

The percentile interval provides a nonparametric inference based on the empirical distribution of cardinal temperatures, is relatively easy to calculate and provides good coverage performance.

All statistical computations were carried out using SAS/STAT (1991) software. 


\section{Description of Data}

\section{EMPIRICAL APPLICATION}

Common crupina (Crupina vulgaris), a winter annual weed from the Mediterranean region, has naturalized at widely scattered rangeland locations in the Pacific Northwest. The invasion was from multiple introductions, confirmed by the presence of two distinct varieties (Couderc-LeVaillant and Roché 1993). Seeds collected from each of the major populations in Idaho, Oregon and Washington included both taxonomic varieties, but may have represented three genetically different populations. The population from Chelan County, Washington was var. brachypapa, while those from Lewis County, Idaho and Umatilla County, Oregon, were both var. typica (Couderc-LeVaillant and Roché 1993). Seeds were collected in late June and early July 1993 with a sweep net. To eliminate the possibility of environmentally induced differences in germination response, seeds for the experiments were grown in a common garden at the University of Idaho Plant Science Farm near Moscow, Idaho. The bulk collected seeds were planted in September 1993 and the following spring flowering stems of individual plants were covered with pollination bags to prevent crossing between population sources. Mature seeds were collected in June 1994, allowed to air dry, then stored in glass jars at approximately $20 \mathrm{C}$ for 4 months. Germination chambers without lights were set at a constant temperature between 4 and $18 \mathrm{C}$. The temperature inside each germinator was monitored during the experiments with thermistors or thermocouples and Campbell Scientific CR21 or Campbell Scientific CR21X data loggers, respectively, reading temperatures at one-minute intervals and recording hourly mean, minimum, and maximum temperatures. Experimental runs in which germination chamber temperatures fluctuated significantly were not included in the study. Twenty-three separate runs were successfully completed. All three populations were tested simultaneously, with 4 replications of 50 seeds per petri dish in each germination chamber. Cumulative germination was recorded every 12 hours until either all achenes had germinated or no additional germination occurred for 5 days. Maximum germination was obtained in 15 to 20 days, depending on temperature. Germination was defined as $5 \mathrm{~mm}$ of radicle protrusion.

\section{Modelling Germination}

For each temperature and population, the time course of germination was modelled using the logistic function (1). In each case the fitted model followed data trends well (Figure 2), showed minimal correlation among parameter estimates (Table 1), and resulted in residual values with acceptable patterns and magnitudes (Figure 3). For example at $10 \mathrm{C}$, all populations achieved from 94 to $98 \%$ maximum germination and the time to $50 \%$ germination was essentially the same across populations (approximately 6 days). The rate of germination, however, displayed some differences. Oregon had the fastest germination rate, $K=4.24$, while Washington was the slowest, $K=2.54$. Idaho had an intermediate value of $K=3.76$.

If all temperatures are considered simultaneously, the problem can be viewed as a three dimensional logistic surface (Figure 4). The contours of such a surface reflect changes in germination percentiles (e.g., $t_{20}, t_{50}, t_{80}$ ) and provide insight into the relationship of germination with time and temperature (Figure 5). The minimum of the curve, corresponding 
to the optimum temperature for germination, remained relatively constant, 10 or $11 \mathrm{C}$, across percentiles. Greater spread between the curves for $t_{20}, t_{50}$, and $t_{80}$ above the optimum temperature indicated a decrease in rate $(K)$ and maximum germination $(M)$ as maximum temperature was approached. Between the optimum and $4 \mathrm{C}$, there was no decrease in maximum germination or rate, only a delay in onset of germination. At $t_{50}$, all three populations exhibited similar curves in the relation of cumulative germination time to temperature (Figure 6).

\section{Estimation of Cardinal Temperatures}

The inverse of the parameter estimate $\mathrm{L}$ was fitted to the parabolic model given in (2). For all populations, this model presented a good fit to the estimated $t_{50}$ values (Figure 7, Table 2), with acceptable residual structure (Figure 8). Comparison of parabolic models used in estimation of cardinal temperatures at $t_{50}$ showed no statistical difference among the three populations (Figure 9).

Bootstrap methods were used to approximate $95 \%$ confidence bounds on the cardinal temperatures using five thousand samples of size fifteen from each population. Each sample provided determinations of the cardinal temperatures, with confidence bounds based on the $5^{\text {th }}$ and $95^{\text {th }}$ percentiles of the cardinal distributions (Table 3). Estimates of optimum temperature for Idaho and Washington populations was 10.6, whereas that of the Oregon population was 10.3. Estimated values of base temperatures were .83, 1.62, and 1.33 for Idaho, Oregon and Washington, respectively. Neither estiamtes for optimum nor base temperatures were significantly different among populations based on overlapping $95 \%$ bootstrap confidence intervals. The estimated value for maximum temperature $(\sim 20 \mathrm{C})$ showed wider confidence bounds across populations.

The biological relevance of the estimates is good for $T_{b}$ and $T_{o}$, based on observations of germination behavior. Also, the estimate of approximately $1 \mathrm{C}$ for $\mathrm{T}_{\mathrm{b}}$ falls nicely within the range of base temperatures reported for other annual species, 0 to $2 \mathrm{C}$ (Monteith 1981). Unfortunately, a maximum temperature of $20 \mathrm{C}$ is too low, because in other experiments common crupina (var. typica) germinated at temperatures as high as 25 and $30 \mathrm{C}$ (Roché, unpublished data), albeit with decreased rate and lower maximum germination, indicating that these temperatures were clearly in the supra-optimal range. Patterson and Mortensen (1985) reported germination of var. typica at alternating temperatures of 29/25, 36/35, 36/18, 36/11, and $36 / 4 \mathrm{C}$, but germination was greatly reduced, especially at a day temperature of $36 \mathrm{C}$ regardless of night temperature. Variety brachypapa did not germinate at temperatures above $30 \mathrm{C}$. The estimated values of cardinal temperatures for population Idaho shifted downward from $t_{20}$ to $t_{50}$ to $t_{80}$ for each of base, optimum and maximum, but was not significant based on overlapping confidence intervals (Figure 10). This indicates relative uniformity of germination rate across temperatures. 


\section{CONCLUSIONS}

An alternative to utilizing traditional methods in seed germination data analysis is the use of empirically derived growth models. These models accurately describe the time course of germination and can be effectively used as the basis for estimating cardinal temperatures. Bootstrap simulation techniques can be used to assess the statistical accuracy of the estimates. Due to the variation in $\mathrm{T}_{\mathrm{b}}$ and $\mathrm{T}_{\mathrm{m}}$ arising from extrapolation as well as the approximate nature of the confidence intervals, their estimated values should be treated with circumspection.

\section{REFERENCES}

Brown, R. F., and D. G. Mayer. 1988. Representing cumulative germination. 2. The use of the Weibull and other empirically derived curves. Ann. Bot. 61: 127-38.

Couderc-LeVaillant, M. and C. T. Roché. 1993. Evidence of multiple introductions of Crupina vulgaris in infestations in the western United States. Madroño 40:63-65.

Dumur, D., C. J. Pilbeam, and J. Craigon. 1990. Use of the Weibull function to calculate cardinal temperatures in faba bean. J. Exp. Bot. 41: 1423-30.

Efron, B. and R. J. Tibshirani. 1993. An Introduction to the Bootstrap. Chapman Hall, NY.

Garcia-Huidobro, J., J. L. Monteith, and G. R. Squire. 1982. Time temperature and germination of pearl millet. I. Constant Temperature. J. Exp. Bot. 33: 288-96.

Janssen, J. G. M. 1973. A method of recording germination curves. Ann. Bot. 37: 705-8.

Kotowski, F. 1926. Temperature relations to germination of vegetable seeds. Amer. Soc. Hort. Sci. Proc. 23: 176-84.

Maguire, J. D. 1962. Speed in germination - Aid in selection and evaluation for seedling emergence and vigor. Crop Sci. 2: 176-7.

Monteith, J. L. 1981. Climatic variation and the growth of crops. Quarterly J. Royal Meterol. Soc. 107: 749-774.

Nicholls, M. A. and W. Heydecker. 1968. Two approaches to the study of germination data. Intl. Seed Test Assn. 33: 531-40.

Orchard, T. J. 1977. Estimating the parameters of plant seedling emergence. Seed Sci. Tech. 5: 61-9. 
Patterson, D. T. and D. A. Mortensen. 1985. Effects of temperature and photoperiod on common crupina (Crupina vulgaris). Weed Sci. 33: 333-339.

SAS Institute Inc. 1991. SAS/STAT User's Guide, Version 6, Fourth Edition. SAS Institute Inc. Cary, NC.

Shafii, B., W. J. Price, J. B. Swensen, and G. A. Murray. 1991. Nonlinear estimation of growth curve models for germination data analysis. Proceedings of the 1991 Kansas State University Conference on Applied Statistics in Agriculture, pp 19-36.

Thompson, C. R., D. C. Thill, and B. Shafii. 1994. Germination characteristics of sulfonylurea-resistant and susceptible kochia (Kochia scoparia). Weed Sci. 42: 50-56.

Timson, J. 1965. New method of recording germination data. Nature 207: 216-17.

Tipton, J. L. 1984. Evaluation of three growth curve models for germination data analysis. J. Amer. Soc. Hort. Sci. 4: 451-54.

Torres, M. and G. Frutes. 1990. Logistic function analysis of germination behavior of aged fennel seeds. Env. Expl. Bot. 30: 383-90.

Tucker, H. and L. N. Wright. 1965. Estimating rapidity of germination. Crop Sci. 5: 398-9. 
Table 1. Logistic model parameters for cumulative germination at $10 \mathrm{C}$ for populations of Crupina vulgaris from Idaho, Oregon, and Washington. Parameter abbreviations are $\mathrm{M}$ for maximum potential germination (\%), L for time (days) to $50 \%$ germination, and $\mathrm{K}$ for rate of increase.

\begin{tabular}{|c|c|c|c|c|c|c|}
\hline Population & Parameter & Estimate & Asymptotic & \multicolumn{3}{|c|}{ Asymptotic Correlations } \\
\hline ID & $\begin{array}{l}\mathrm{M} \\
\mathrm{L} \\
\mathrm{K}\end{array}$ & $\begin{array}{c}98.39 \\
5.92 \\
3.76\end{array}$ & $\begin{array}{l}0.38 \\
0.02 \\
0.37\end{array}$ & $\begin{array}{r}1.00 \\
0.10 \\
-0.16\end{array}$ & $\begin{array}{l}0.01 \\
1.00 \\
0.44\end{array}$ & $\begin{array}{r}-0.16 \\
0.44 \\
1.00\end{array}$ \\
\hline OR & $\begin{array}{l}\mathrm{M} \\
\mathrm{L} \\
\mathrm{K}\end{array}$ & $\begin{array}{c}94.62 \\
5.83 \\
4.24\end{array}$ & $\begin{array}{l}0.68 \\
0.40 \\
0.83\end{array}$ & $\begin{array}{r}1.00 \\
0.07 \\
-0.09\end{array}$ & $\begin{array}{l}0.07 \\
1.00 \\
0.76\end{array}$ & $\begin{array}{r}-0.09 \\
0.76 \\
1.00\end{array}$ \\
\hline WA & $\begin{array}{l}\mathrm{M} \\
\mathrm{L} \\
\mathrm{K}\end{array}$ & $\begin{array}{c}96.28 \\
5.99 \\
2.54\end{array}$ & $\begin{array}{l}0.36 \\
0.02 \\
0.13\end{array}$ & $\begin{array}{r}1.00 \\
0.23 \\
-0.22\end{array}$ & $\begin{array}{l}0.23 \\
1.00 \\
-0.04\end{array}$ & $\begin{array}{r}-0.22 \\
-0.04 \\
1.00\end{array}$ \\
\hline
\end{tabular}

Table 2. Quadratic model parameter estimates for inverse time to $50 \%$ germination for populations of Crupina vulgaris from Idaho, Oregon, and Washington.

\begin{tabular}{cccc}
\hline \hline Population & Parameter & Std Error & $\underline{\mathbf{P}>|\mathbf{t}|}$ \\
& $\beta_{0}-0.0293$ & 0.0289 & 0.3257 \\
ID & $\beta_{1} 0.0368$ & 0.0061 & 0.0001 \\
& $\beta_{2}-0.0017$ & 0.0003 & 0.0001 \\
\hline \multirow{2}{*}{ OR } & $\beta_{0}-0.0724$ & 0.0275 & 0.0159 \\
& $\beta_{1} 0.0484$ & 0.0056 & 0.0001 \\
& $\beta_{2}-0.0023$ & 0.0003 & 0.0001 \\
\hline \multirow{2}{*}{ WA } & $\beta_{0}-0.0509$ & 0.0178 & 0.0097 \\
& $\beta_{1} 0.0410$ & 0.0037 & 0.0001 \\
& $\beta_{2}-0.0019$ & 0.0002 & 0.0001 \\
\hline \hline
\end{tabular}


Table 3. Estimated cardinal temperatures with approximate $95 \%$ confidence limits for populations of Crupina vulgaris from Idaho, Oregon, and Washington.

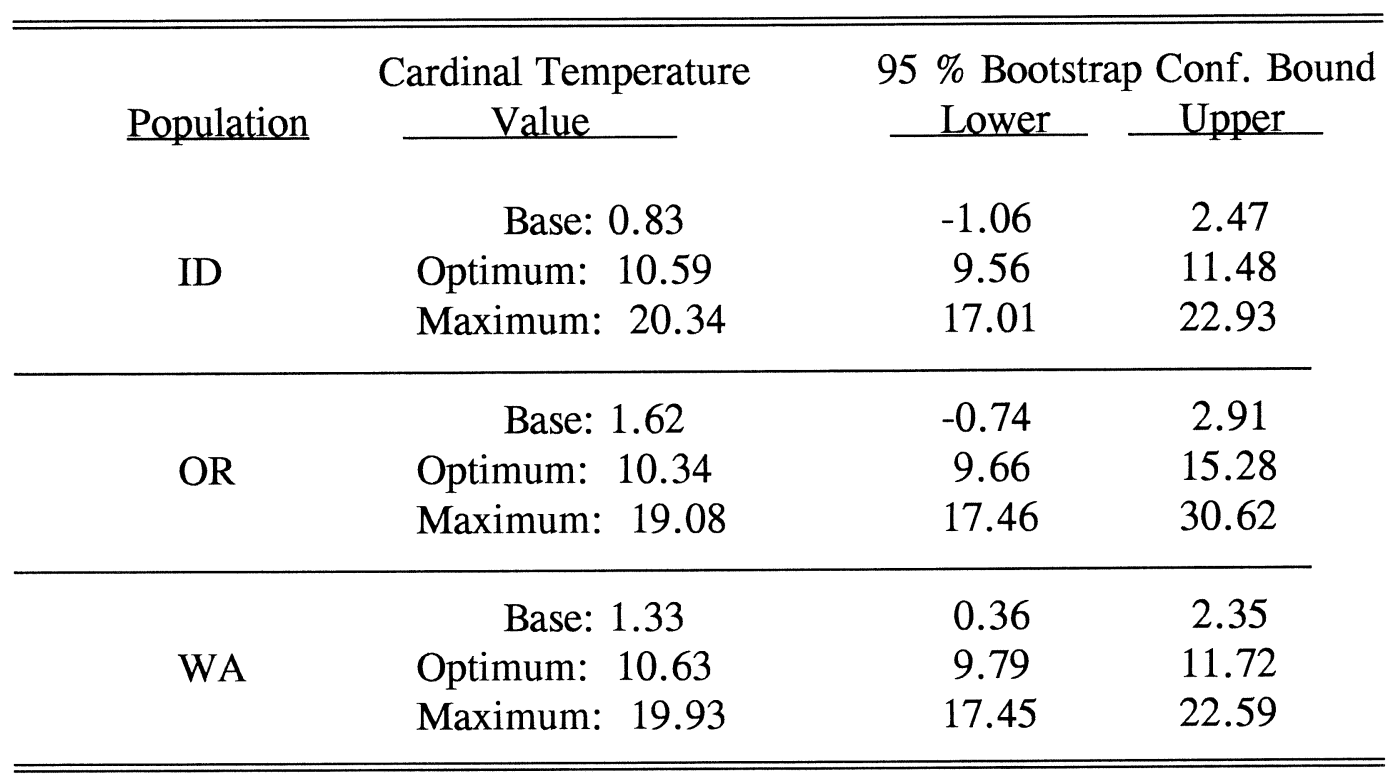

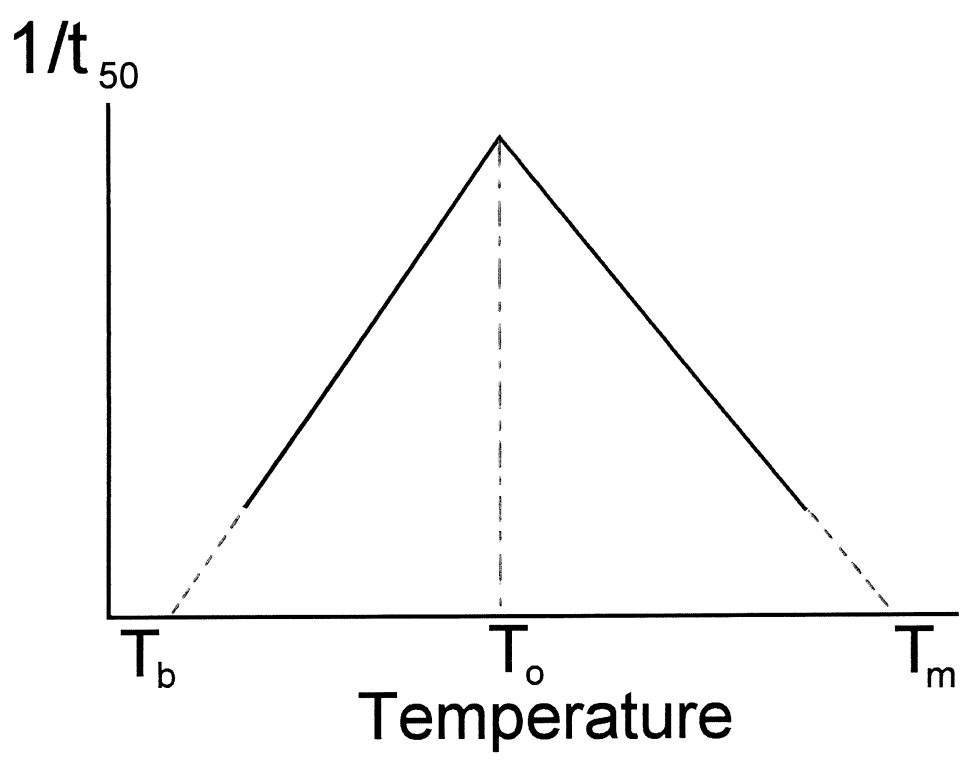

Figure 1 Relationship between $1 / t_{50}$ and cardinal temperatures. 

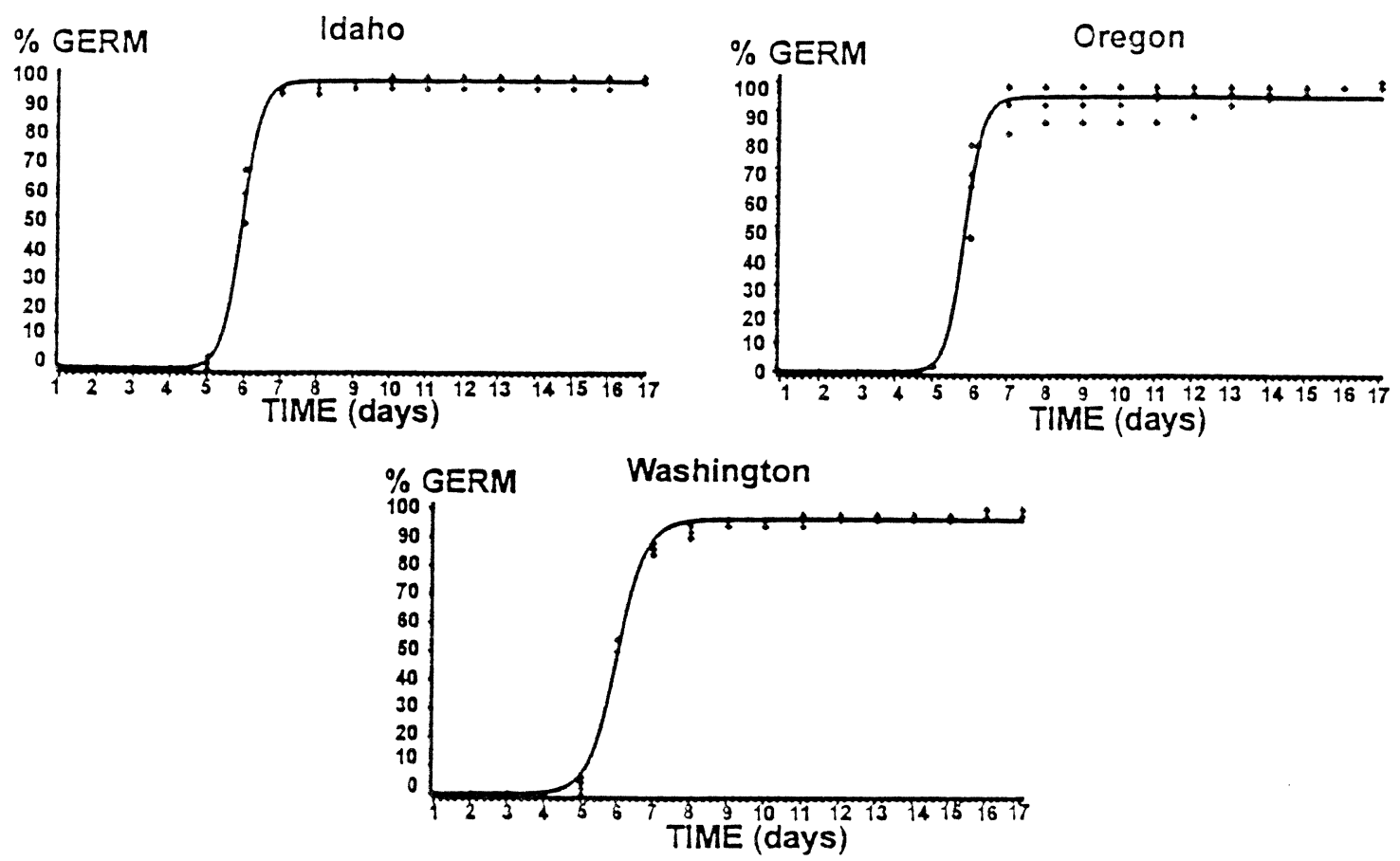

Figure 2. Logistic Model fit to cumulative germination at $10 \mathrm{C}$ for populations of Crupina vulgaris from Idaho, Oregon, and Washington.
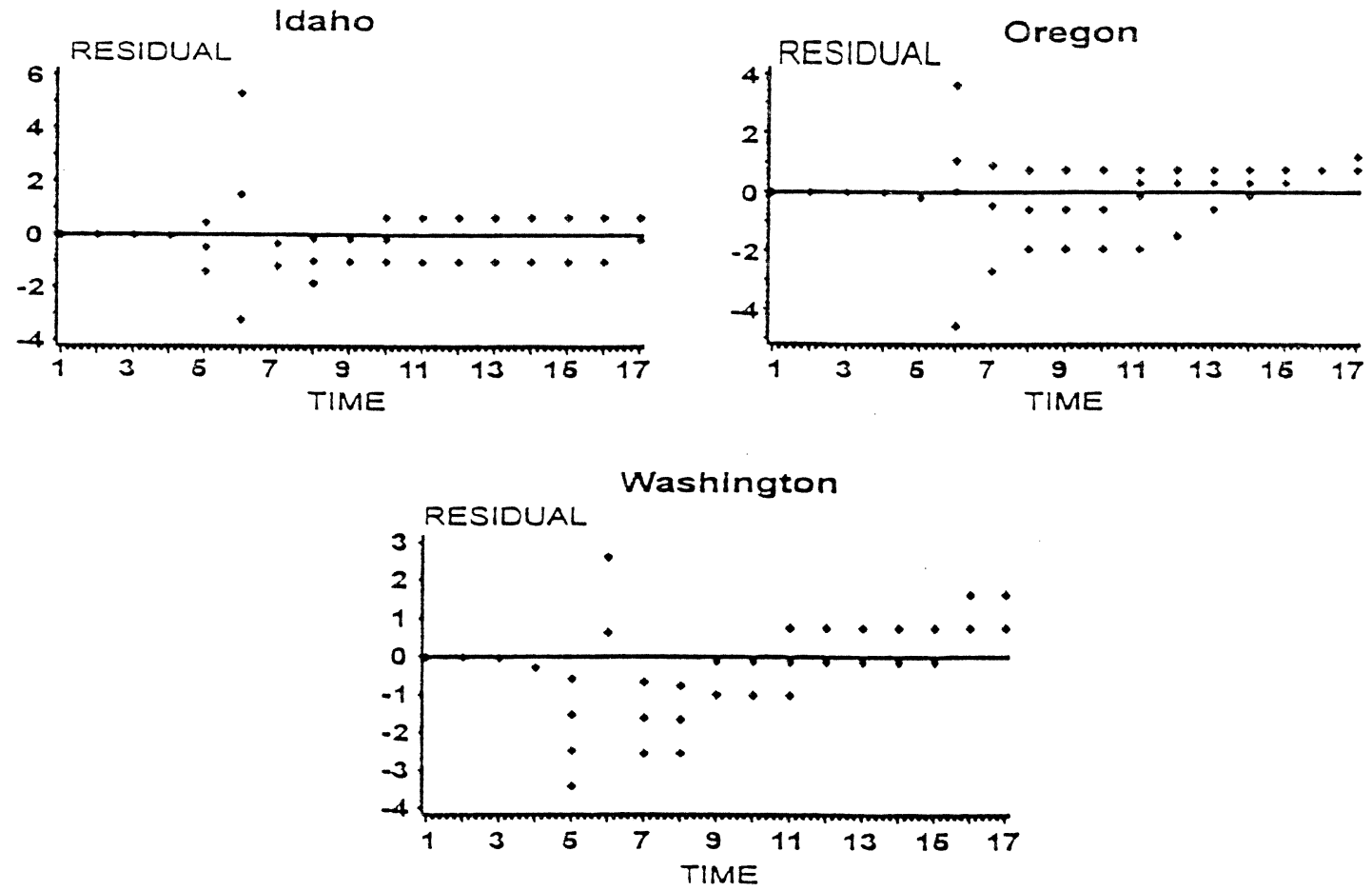

Figure 3. Plot of residual structures for logistic model tits to cumulative germination at iU $\mathrm{C}$ of Crupina vulgaris from Idaho, Oregon, and Washington. 


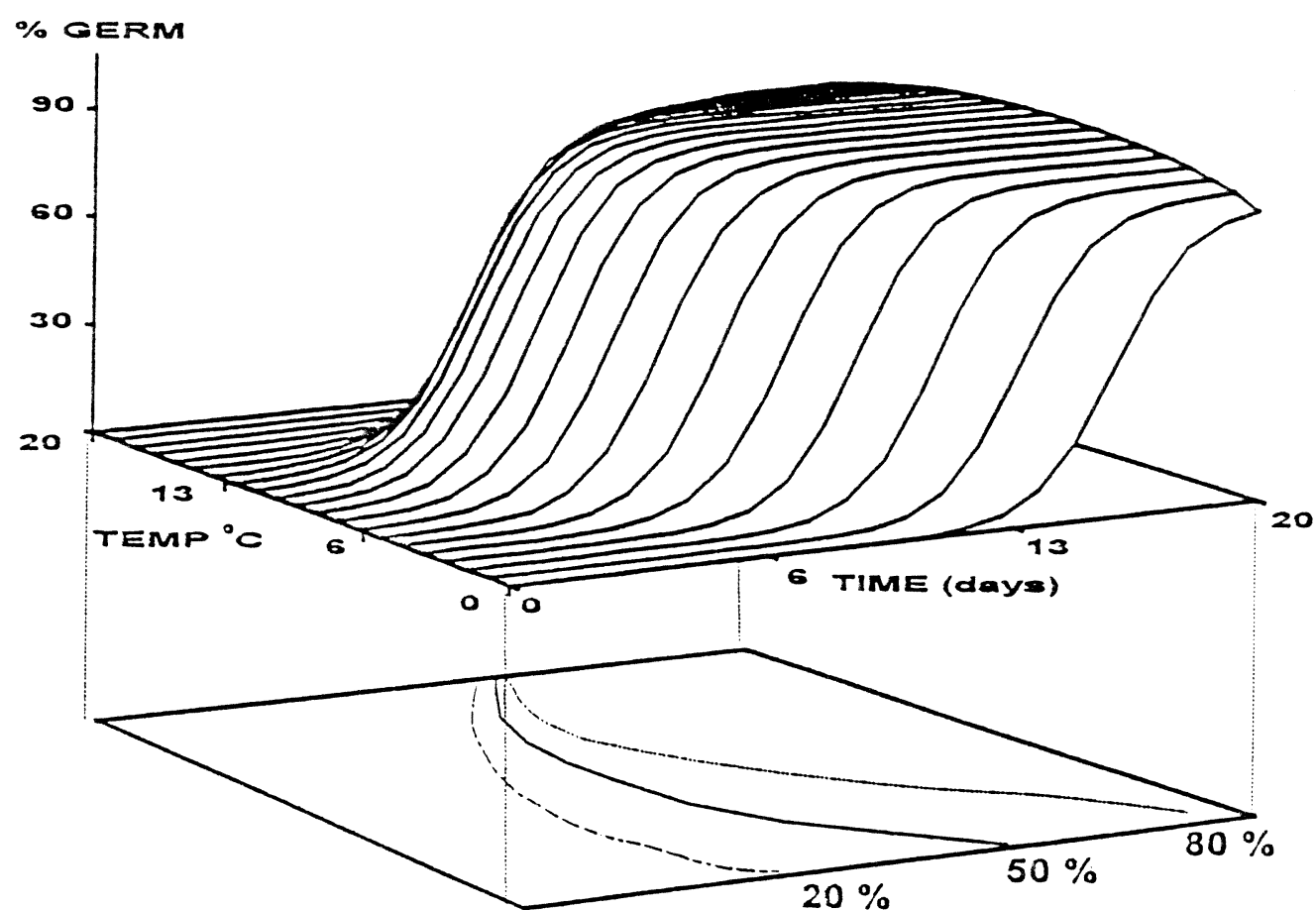

Figure 4. Three dimensional logistic surface for cumulative germination curves at all temperatures over time.

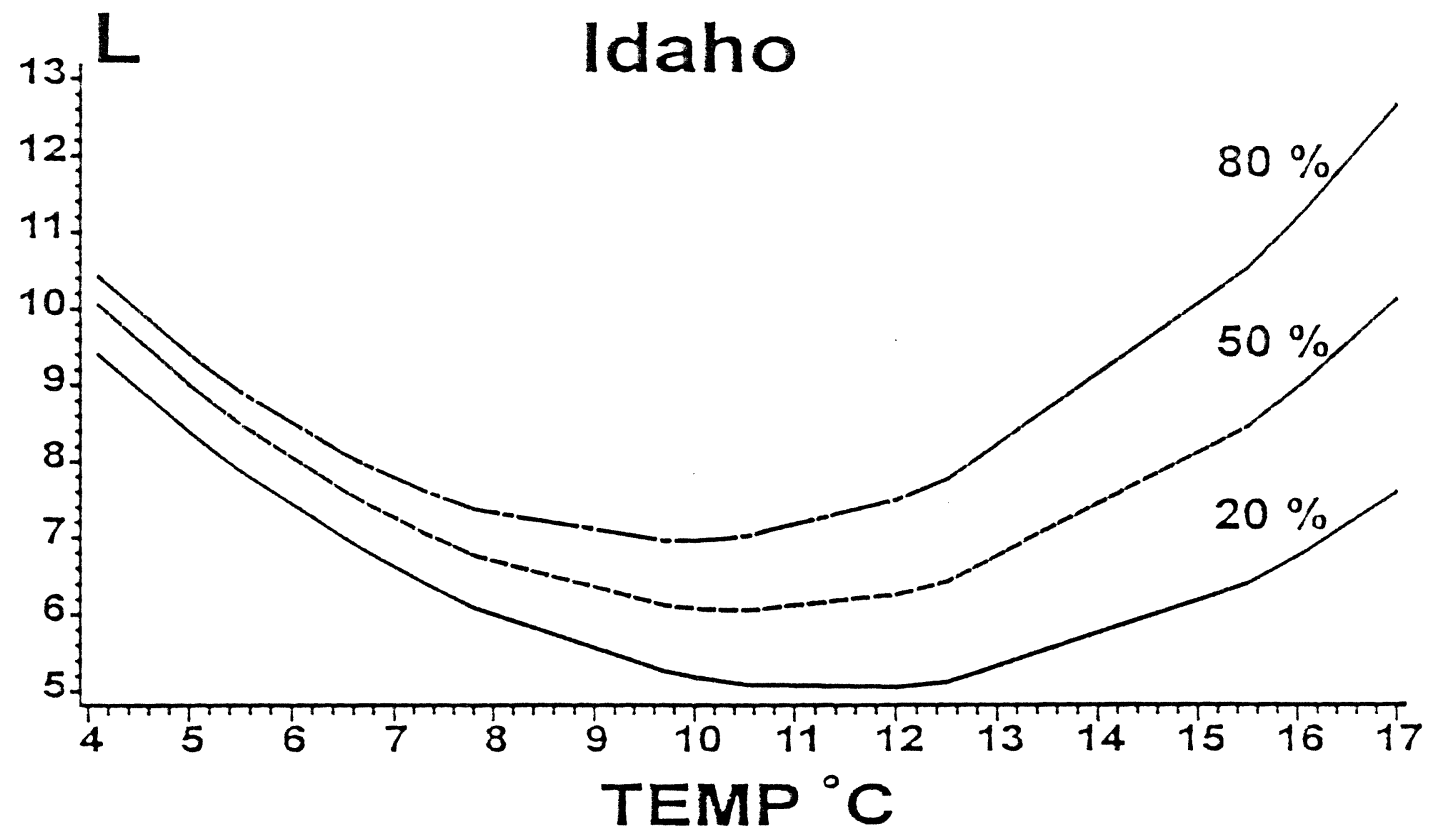

Figure 5. Relationship between 20,50 , and $80 \%$ cumulative germination and temperature for the Idaho Crupina vulgaris population. 

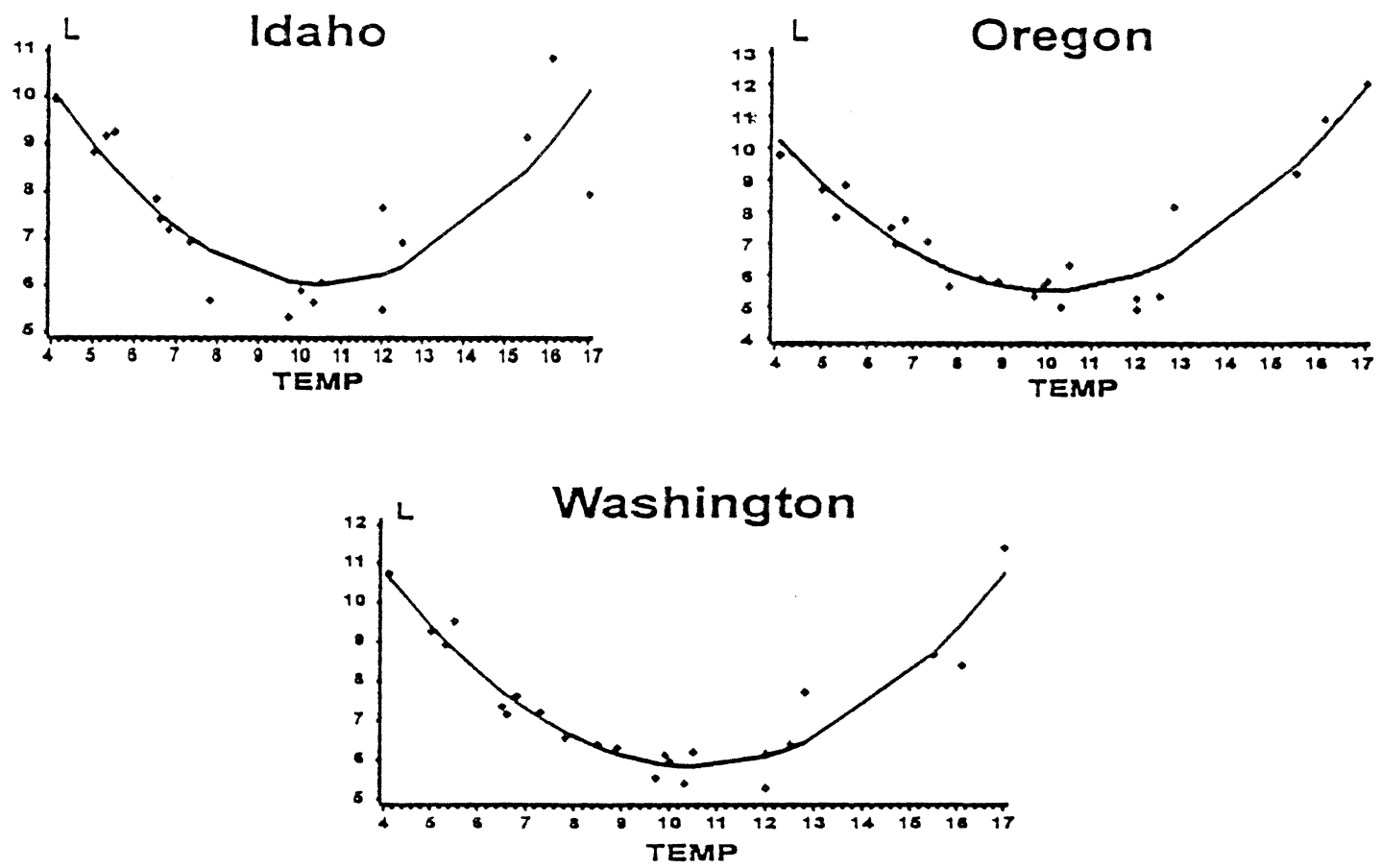

Figure 6. Curvilinear relationship between time to 50\% germination and temperature for populations of Crupina vulgaris from Idaho, Oregon, and Washington.
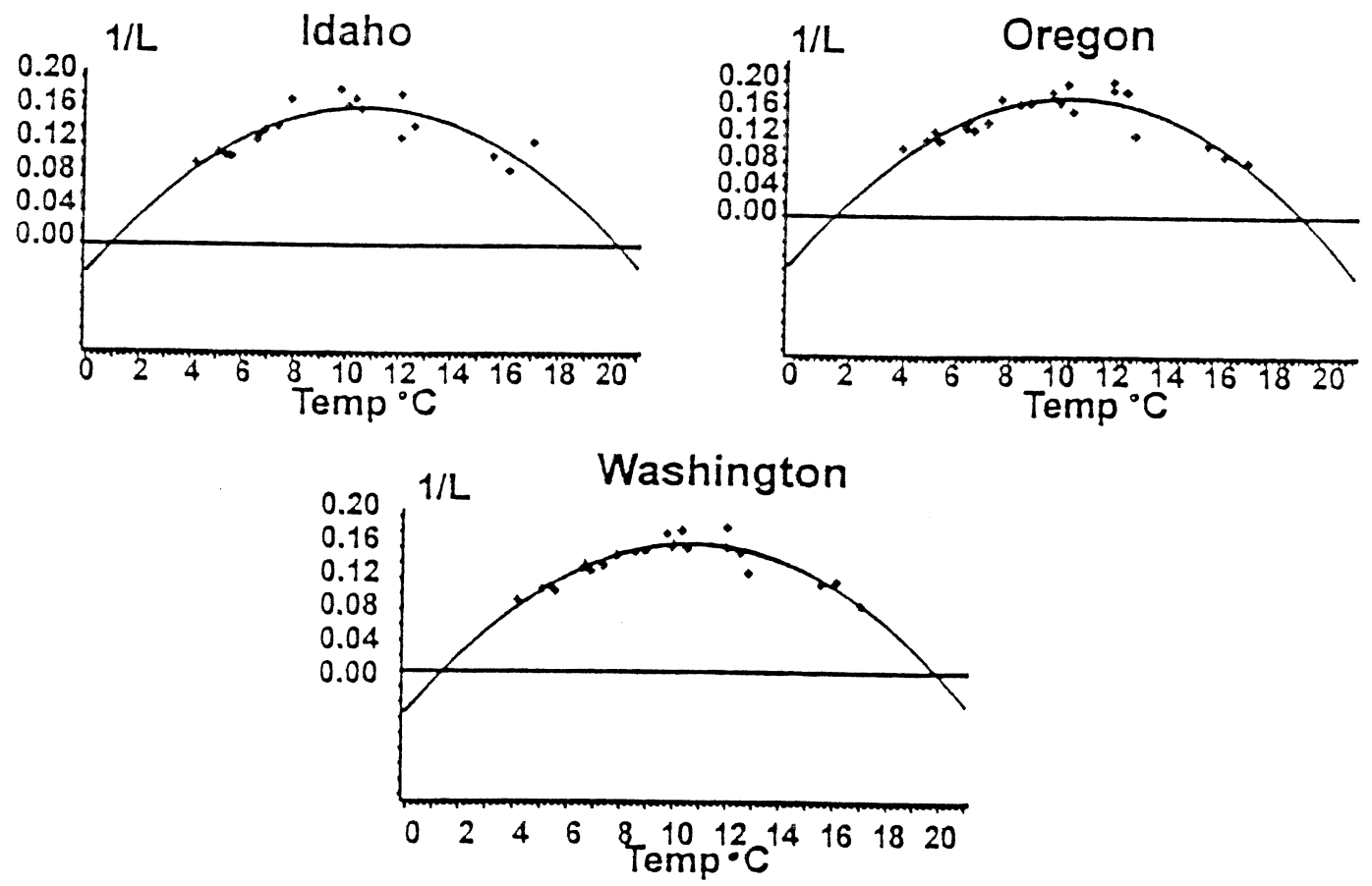

Figure 7. Relationship between rate of germination $\left(1 / \mathrm{L}=1 / \mathrm{t}_{50}\right)$ and temperature, showing extrapolated base and maximum temperature for populations Idaho, Oregon, and Washington. 

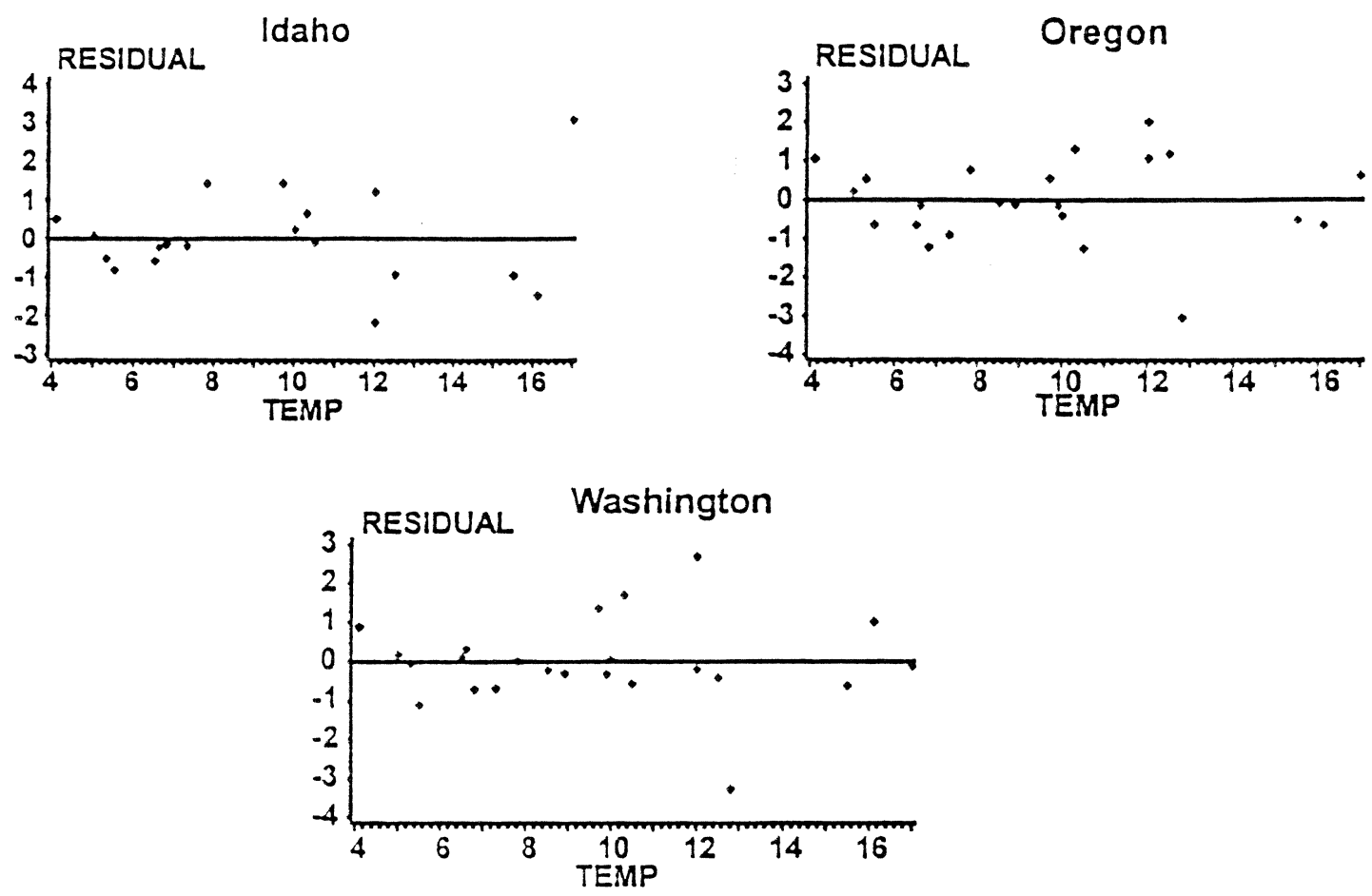

Figure 8. Residual structures for regressions of germination rate $\left(1 / \mathrm{L}=1 / \mathrm{t}_{50}\right)$ against temperature for Idaho, Oregon and Washington populations.

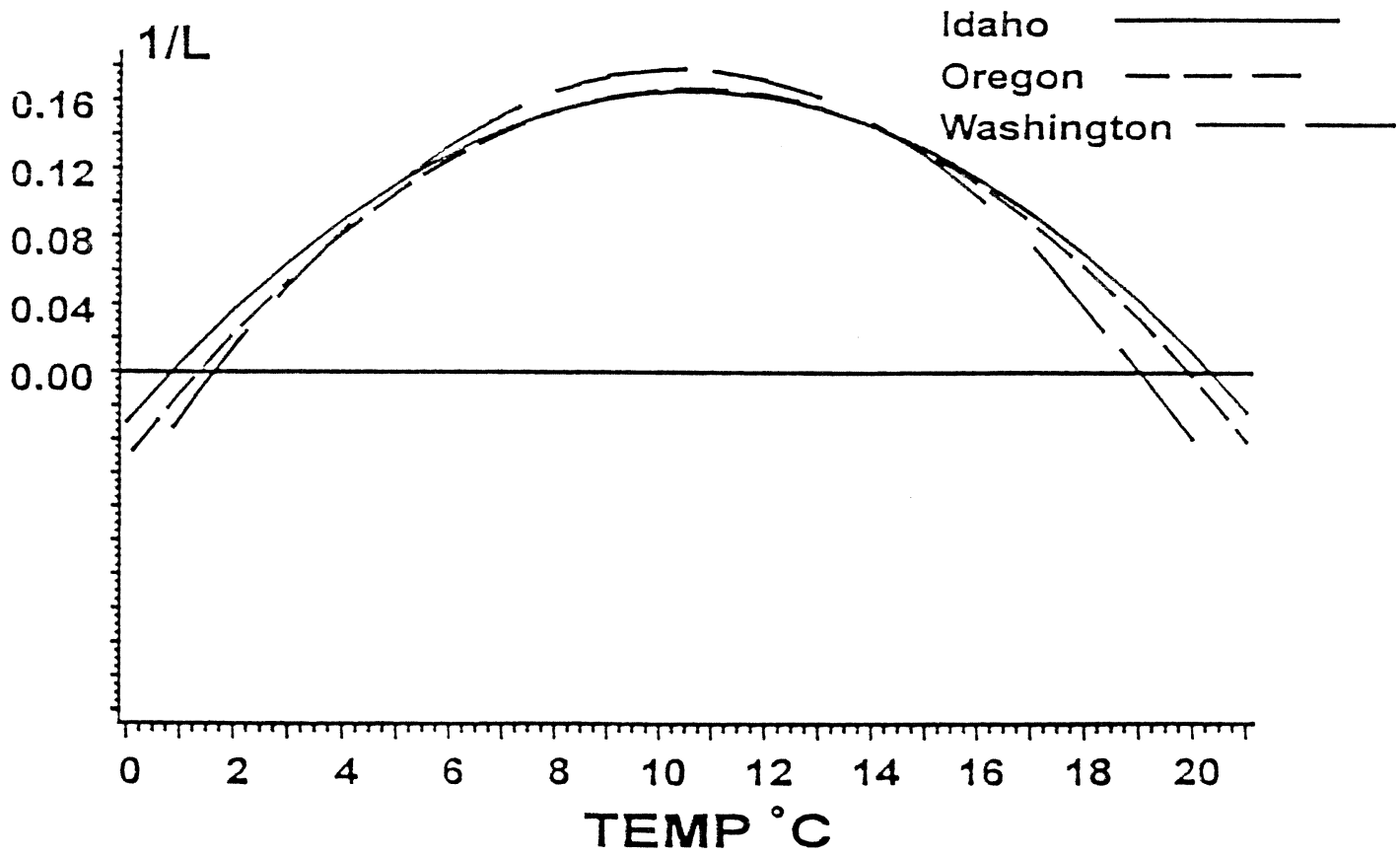

Figure 9. Comparison of cardinal temperature curves for Idaho, Oregon and Washington populations. 


\section{IDAHO}

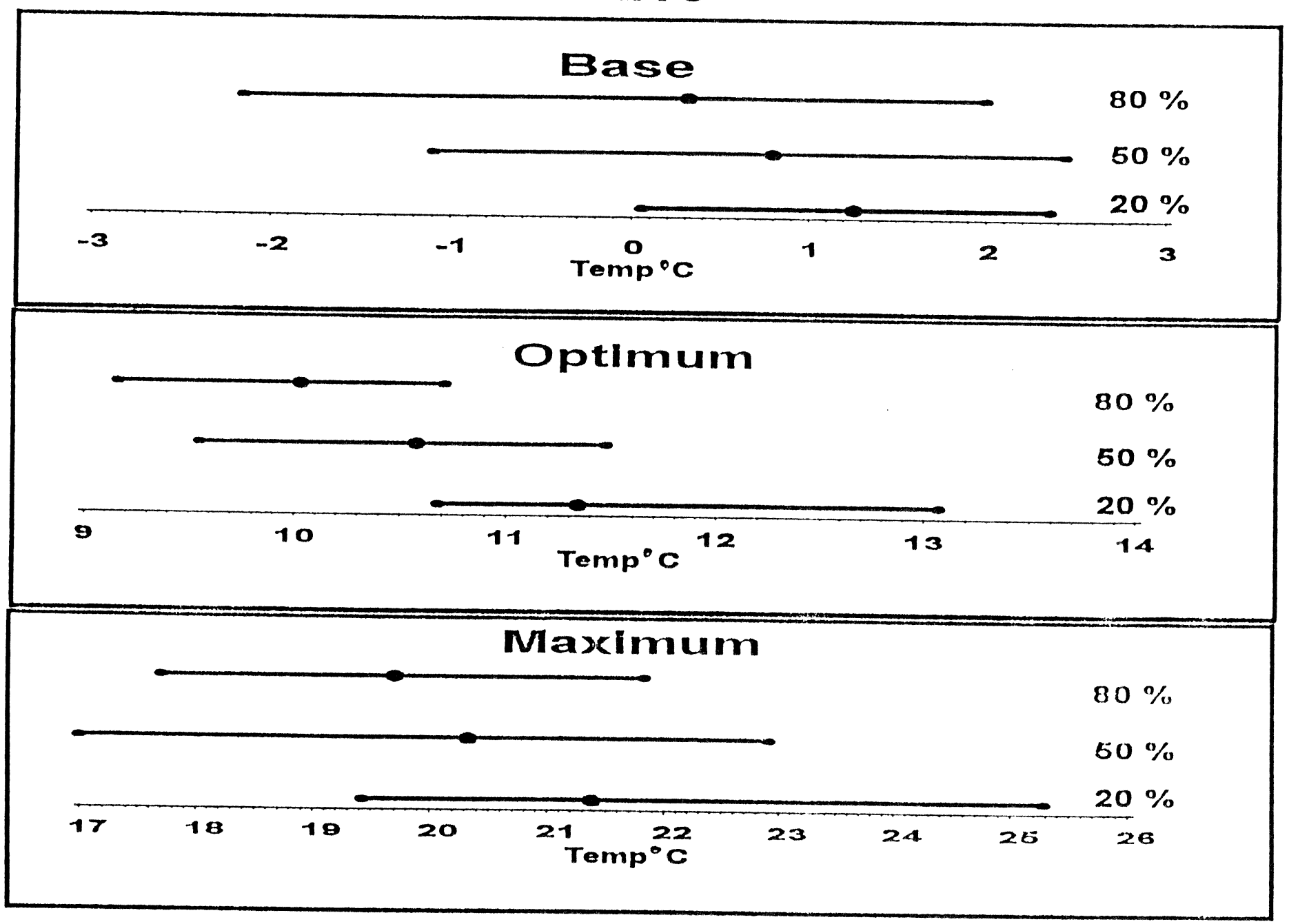

Figure 10. Comparison of estimated cardinal temperatures and their corresponding $95 \%$ bootstrap confidence intervals and 20 , 50 and $80 \%$ cumulative germination for the Idaho population. 